\title{
Increased pathological complete response rate after a long-term neoadjuvant letrozole treatment in postmenopausal oestrogen and/or progesterone receptor-positive
} breast cancer

\begin{abstract}
G Allevi ${ }^{1}$, C Strina ${ }^{1}$, D Andreis ${ }^{1}$, V Zanoni ${ }^{1}$, L Bazzola ${ }^{1}$, S Bonardi ${ }^{1}$, C Foroni ${ }^{1}$, M Milani ${ }^{1}$, M R Cappelletti ${ }^{1}$, F Gussago ${ }^{1}$, S Aguggini ${ }^{1}$, R Giardini ${ }^{2}$, M Martinotti ${ }^{3}$, S B Fox ${ }^{4,5}$, A L Harris ${ }^{6}$, A Bottini ${ }^{1}$, A Berruti ${ }^{7}$ and D Generali*,1

${ }^{1}$ U.O. Multidisciplinare di Patologia Mammaria, Laboratorio di Oncologia Molecolare Senologica, A.O. Istituti Ospitalieri di Cremona, Viale Concordia 1, Cremona 26100, Italy; ${ }^{2}$ U.O. Anatomia Patologica, A.O. Istituti Ospitalieri di Cremona, Cremona, Italy; ${ }^{3}$ Chirurgia Generale, Dipartimento Chirurgico, A.O. Istituti Ospitalieri di Cremona, Cremona, Italy; ${ }^{4}$ Peter MacCallum Cancer Centre, St Andrews Place, East Melbourne, Melbourne, Victoria, Australia; ${ }^{5}$ Department of Pathology, University of Melbourne, Melbourne, Victoria, Australia; ${ }^{6}$ Molecular Oncology Laboratories, Weatherall Institute of Molecular Medicine, University of Oxford, John Radcliffe Hospital, Oxford OX3 9DS, UK and 'Oncologia Medica, Spedali Civili di Brescia, Università di Brescia, Brescia, Italy
\end{abstract}

Background: The objective of this study was to determine the optimal scheduling of $2.5 \mathrm{mg}$ daily letrozole in neoadjuvant breast cancer patients to obtain pathological complete response (pathCR) and assess Ki-67 expression as an early predictor of response.

Patients and methods: This single institution study comprised 120 oestrogen receptor (ER)-positive postmenopausal women with primary breast cancer (clinical stage $\geqslant T 2, N 0-1$ ), from three sequential cohorts (cohort A of 40 , cohort B of 40 and cohort $C$ of 40 patients, respectively) based on different duration of the neoadjuvant letrozole. Biological markers such as ER, progesterone receptor, HER2 and Ki-67 expression were tested at diagnosis and at definitive surgery.

Results: A total of 89 patients (75.4\%) achieved an objective response with 44 (37.3\%) clinical CRs and 45 (38.1\%) partial responses. The clinical CRs were significantly observed in cohort C (23 out of 40 patients, $57.5 \%$ ) and B (16 out of 38 patients, 42.1\%) compared with cohort A (5 out of 40 patients, $12.5 \%$ ) ( $P$-value for trend $<0.001$ ). Letrozole induced a similar significant reduction in $\mathrm{Ki}-67$ index after treatment in all cohorts. The pathCR rate was significantly more frequent in cohort C (7 out of 40 patients, 17.5\%) than in cohort A (1 out of 40 patients, $2.5 \%)$ and B (2 out of 40 patients, $5.0 \%)(P$-value for trend $<0.04)$.

Conclusion: One-year neoadjuvant letrozole therapy leads to a higher pathCR rate and may be the optimal length of drug exposure. 
Neoadjuvant therapy (NeoT) is commonly used as a preoperative treatment to favour a volume reduction of locally advanced breast cancers, to achieve the highest possible rates of breast-conserving surgery (BCS). Moreover, its use in clinical routine has become increasingly important to test the in vivo sensitivity of breast cancer to various therapeutic approaches (Bottini et al, 2006; Berruti et al, 2008).

The management of the elderly patient with breast cancer is a challenge to the breast care team for a number of reasons. The higher rate of comorbidity in elderly patients increases the risk for complications and mortality following surgery and other adjuvant treatments such as chemotherapy and radiotherapy (Yancik et al, 2001). The use of endocrine therapy in the neoadjuvant setting allows disease control and downstaging of tumours to enable less extensive surgery, with less morbidity compared with other available treatments. Aromatase inhibitors have been shown to be superior to tamoxifen and are being tested extensively as NeoT in place of tamoxifen (Eiermann et al, 2001; Smith et al, 2005). Response rates between $40 \%$ and $60 \%$ have been reported with aromatase inhibitors in randomised clinical trials (Eiermann et al, 2001; Smith et al, 2005).

Although endocrine therapy in the NeoT setting is recognised to induce a significant reduction of tumour volume in hormone receptor-positive postmenopausal women after just 3-4-months of treatment (Eiermann et al, 2001; Smith et al, 2005; Mlineritsch et al, 2008), the optimal treatment duration has not been established.

Our group has previously shown that $2.5 \mathrm{mg}$ letrozole administered for 6 months in elderly breast cancer patients receiving primary systemic treatment induced an overall response rate in 41 out of 57 patients $(71.9 \%$; $95 \%$ CI, 60.8-83.8), with two cases $(3.5 \%)$ of pathological complete response (pathCR) (Bottini et al, 2006). To investigate Ki-67 expression as a surrogate parameter of treatment efficacy (Berruti et al, 2011a), we showed that letrozole alone also induced a significant reduction of Ki-67 (evaluated at diagnosis and at definitive surgery) expression after treatment (Bottini et al, 2006).

Only three groups have explored longer ( $>6$ months) administration and the overall response rate (Krainick-Strobel et al, 2008; Dixon et al, 2009; Carpenter et al, 2010). Dixon et al (2009), in their prospective study assessing the response to 3-12 months neoadjuvant treatment with letrozole, showed tumour shrinkage continuing up to 12 months in responders. Krainick-Strobel et al (2008)showed that the prolonged treatment could be safely and effectively used for up to 8 months, resulting in further clinical tumour volume reduction (70\%) compared with $62.5 \%$ obtained in patients treated for 4 months. Although these studies showed that letrozole could be safely and effectively used for at least 8 months in the neoadjuvant setting, to date, there are no data on the pathological response rate using different durations of letrozole to guide optimal therapy for patients in the NeoT context. Therefore, we undertook this study to investigate the potential biological benefits of extended neoadjuvant letrozole therapy comparing 4 months vs 8 months $v s 12$ months of letrozole administration in neoadjuvant setting, in sequential patient cohorts, aiming at the identification of the optimal treatment duration to obtain maximum response and identify characteristics associated with pathCR. As pathCR is a prognostic factor for survival (Kaufmann et al, 2006; Berruti et al, 2011a), the main objective of the study was to evaluate the rate of pathCR after primary systemic treatment with letrozole. Secondary objectives were the rate of clinical and radiological response, tolerability and the variation of Ki-67.

\section{MATERIALS AND METHODS}

Patients. Elderly women (age $\geqslant 65$ years) unfit for chemotherapy from April 2004 to February 2011 with clinical T2-4 N0-1 M0 (evaluated with clinical and radiological procedures) and oestrogen receptor-positive $(\mathrm{ER}+)$ and/or progesterone receptor-positive $(\mathrm{PgR}+)$ breast cancer were eligible, from three sequential patient cohorts (40 each in single cohort) received different duration of the neoadjuvant treatment with letrozole (Femara, Novartis, Milan, Italy) $2.5 \mathrm{mg}$ (one tablet) daily: 4 (cohort A) or 8 (cohort B) or 12 (cohort C) months of treatment. They had an Eastern Cooperative Oncology Group performance status of two or lower, adequate bone marrow reserve (WBC count, $>3.5 \times 10^{9} 1^{-1}$; platelets, $>100 \times 10^{9} \mathrm{l}^{-1}$; haemoglobin, $\left.>10 \mathrm{~g} \mathrm{dl}^{-1}\right)$, hepatic function (AST/ALT bilirubin and alkaline phosphatase levels $<1.25 \times$ the upper limit of normal value) and renal function (serum creatinine $<1.25 \times$ the upper limit of normal value). The study was approved by the local ethical committee (no. 21391/2012). Written informed consent was obtained before collecting data.

Treatment evaluation and adverse effects. On presentation, an incision biopsy was performed on each patient and a small tissue sample $\left(0.5-0.8 \mathrm{~cm}^{3}\right)$ removed. Each month, to determine clinical tumour response, the size of the primary tumour was measured with a calipre by the same clinician. The clinician also provided at every visit the monthly letrozole tablets to monitor the patients' adherence to the trial. At baseline and at the end of treatment before definitive surgery, mammography and breast ultrasound were performed. Clinical responses were evaluated according to both radiological (breast ultrasound or mammography) and clinical evaluation, by measuring the largest diameter of the tumour and were graded according to Response Evaluation Criteria In Solid Tumours (RECIST) Version 1.1 (Eisenhauer et al, 2009). CR was defined as the disappearance of all known disease. Similarly, partial response (PR) was considered to have occurred if tumour size decreased by at least $30 \%$ in the absence of any progression or new lesions. Decreases by $<30 \%$ and increases by $<20 \%$ were considered to represent stable disease, whereas increases $\geqslant 20 \%$ or appearance of new lesions were classed as progressive disease.

PathCR was defined as a total absence of neoplastic cells in the breast and in the axillary lymph nodes after histological examination: the presence of intraductal carcinoma was not required for pathCR. Surgery was planned after full clinical reassessment. Quadrantectomy or radical mastectomy was performed when indicated in association with full axillary node dissection.

Toxicity was evaluated according to Common Terminology Criteria for Adverse Events (CTCAE, 2009) Version 4.03 (Rockville, MD, USA). No letrozole dose reduction was planned. Letrozole was planned to be interrupted in case of severe adverse events, defined as any undesirable experience associated with the use of the medical product in a patient.

Immunohistochemistry. Immunohistochemical evaluation was performed on formalin-fixed, paraffin-embedded tumour samples obtained at diagnosis and at definitive surgery. ER, PgR, overexpression of HER2 and Ki-67 staining were carried out at the Pathology Unit of the Azienda Ospedaliera Istituti Ospitalieri of Cremona (Italy). The immunohistochemical methodology is fully described elsewhere (Generali et al, 2009). The value of Ki-67 labelling index was used as a cutoff in distinguishing tumours with low $(<14 \%)$ and high $(\geqslant 14 \%)$ proliferative fraction (Berruti et al, 2011b; Fasching et al, 2011; Sheri and Dowsett, 2012).

Statistical analysis. Data were evaluated for non-normality distribution using graphical and descriptive techniques. A test for overall comparison was employed for each outcome variable across all three cohorts (A, B and C), and if a significant difference was detected, we proceeded to pairwise comparisons (i.e., $\mathrm{A} v s \mathrm{~B}, \mathrm{~B} v s$ $\mathrm{C}, \mathrm{A} v s \mathrm{C}$ ) using the $\chi^{2}$ test or Fisher's exact test when indicated for dichotomous variables, and Mann-Whitney $U$-test for continuous variables. Changes in Ki-67 labelling index within cohorts were 
tested with the Wilcoxon signed-rank test. All tests were two sided; $P<0.05$ was considered as statistically significant. Data were analysed using the Statistica software (StatSoft Inc., Tulsa, OK, USA).

\section{RESULTS}

The median age at the start of treatment for all patients was 78.4 years (range 65.0-95.4 years). Tumoral characteristics at baseline were: $100 \%$ (120 out of 120 cases) positive ER whose intensity was $>90 \% ; 82.5 \%$ (99 out of 120 cases) positive PgR; and $6.7 \%$ ( 8 out of 120 cases) positive HER2. Median Ki-67 was $14.5 \%$ (range 2-90\%): $48.3 \%$ (58 out of 120 cases) with low, and $51.7 \%$ (62 out of 120 cases) with high proliferative fraction. The most frequent histological type was infiltrating ductal carcinoma (85 out of 120 cases, $70.8 \%$ ) followed by infiltrating lobular carcinoma (18 out of 120 cases, $15.0 \%$ ), mixed ductal and lobular carcinoma ( 8 out of 120 cases, $6.7 \%$ ) and others (9 out of $120,7.5 \%$ ).

Patients' baseline characteristics according to cohorts are outlined in Table 1. The three cohorts of patients were comparable in all variables.

Treatment toxicity. Adverse events occur in 29 out of 120 patients (24.2\%). The most frequent relevant adverse events (grade 2 ) recorded were hot flashes in 13 patients (44.8\%), osteoarticular pain in 6 patients $(20.7 \%)$, dizziness in 3 patients $(10.3 \%)$, weight gain in 2 patients $(6.9 \%)$ and headache in 2 patients $(6.9 \%)$. No patients interrupted or delayed the treatment. In two patients, grade 3 adverse events were monitored: one with dizziness and one with osteoarticular pain. In these patients, treatment was discontinued after definite surgery.

Treatment response. The clinical response recorded for each cohort is described in Table 2. The majority of PR and CR were observed in cohort C (38 out of 40, objective response rate $(\mathrm{ORR})=95.0 \%(95 \%$ confidence interval, CI: $83.1-99.4 \%))$ as opposed to cohort B (33 out of 38, ORR $=86.8 \%(95 \% \mathrm{CI}$ : $71.9-95.6 \%)$ ) or A $(18$ out of $40, \mathrm{ORR}=45.0 \%$ (95\% CI: $29.3-$ $61.5 \%)$ ). The clinical ORR was higher in cohort $\mathrm{C}$ compared with A $(P$-value for trend $<0.00001)$, and B compared with A ( $P$-value for trend $<0.001)$. The clinical $\mathrm{CR}$ rate compared with non-CR rate was confined to cohorts $\mathrm{C}$ and $\mathrm{B}$ rather than cohort $\mathrm{A}$ ( $P$-value for trend $<0.001)$. Six out of 120 patients, mainly confined in cohort A (five patients), who received the shorter administration of letrozole, progressed under treatment, suggesting the possible primary/de novo activation of pathways involved in aromatase inhibitors' resistance (Margariti et al, 2011; Cavazzoni et al, 2012).

ORR was $49.6 \%$ (58 out of 117 cases (95\% CI: $40.2-59.0 \%)$ ) at month 4, 85.3\% (64 out of 75 cases (95\% CI: $75.3-92.4 \%)$ ) at month 8 and $95.0 \%$ (38 out of 40 cases (95\% CI: 83.1-99.4\%)) at month 12 of treatment compared with baseline (Table 3 ).

The pathCR was confined to the cohort C (7 out of 40 cases, $17.5 \%)$, with respect to cohort B (2 out of 40 cases, $5.0 \%)$ and cohort A (1 out of 40 cases, $2.5 \%$ ) ( $P$-value for trend $<0.04$ ).

As previously shown by our group (Fiorentino et al, 2001), the grade of response of breast cancer to primary chemotherapy, showed by mammography and echography (data not shown), was less marked than the grade of response seen at clinical examination. The frequency of early treatment discontinuation, resulting from disease progression and patient refusal, did not occur among the treatment cohorts.

Breast surgery. All patients treated with letrozole in each cohort underwent surgery no later than 30 days after taking the last dose of study drug. The use of letrozole in neoadjuvant setting enabled a more conservative surgical approach: 101 (84.2\%) out of 120 patients underwent BCS (lumpectomy). In cohort A, 32 (80.0\%)
Table 1. Patients' characteristics (absolute and percentage value) according to single cohort

\begin{tabular}{|c|c|c|c|}
\hline & Cohort A & Cohort B & Cohort C \\
\hline \multicolumn{4}{|l|}{ Age (years) } \\
\hline $\begin{array}{l}\text { Median } \\
\text { Range }\end{array}$ & $\begin{array}{c}79.4 \\
67.5-93.8\end{array}$ & $\begin{array}{c}75.0 \\
67.2-95.4\end{array}$ & $\begin{array}{c}78.51 \\
65.0-88.4\end{array}$ \\
\hline No. of patients & 40 & 40 & 40 \\
\hline
\end{tabular}

PgR status
\begin{tabular}{|l|r|r|r|}
\hline $\mathrm{PgR}+$ & $35(87.5)$ & $32(80.0)$ & $32(80.0)$ \\
$\mathrm{PgR}-$ & $5(12.5)$ & $8(20.0)$ & $8(20.0)$
\end{tabular}

\section{HER-2 status}

\begin{tabular}{|l|c|c|c|}
\hline HER2 + & $2(5.0)$ & $5(12.5)$ & $1(2.5)$ \\
HER2 - & $38(95.0)$ & $35(87.5)$ & $39(97.5)$ \\
\hline
\end{tabular}

\section{Ki-67 expression}

\begin{tabular}{|l|c|c|c|}
\hline Median & 13 & 13.5 & 15 \\
Range & $5-35$ & $2-90$ & $2-32$ \\
$<14 \%$ & $21(52.5)$ & $20(50.0)$ & $17(42.5)$ \\
$\geqslant 14 \%$ & $19(47.5)$ & $20(50.0)$ & $23(57.5)$ \\
\hline
\end{tabular}

\section{Grade}

\begin{tabular}{|l|c|c|c|}
\hline I & $2(5.0)$ & 0 & 0 \\
II & $24(60.0)$ & $27(67.5)$ & $23(57.5)$ \\
III & $13(32.5)$ & $13(32.5)$ & $17(42.5)$ \\
NA & $1(2.5)$ & 0 & 0 \\
\hline
\end{tabular}

\section{Histotype}

\begin{tabular}{|l|c|c|c|}
\hline DIC & $24(60.0)$ & $32(80.0)$ & $29(72.5)$ \\
LIC & $8(20.0)$ & $5(12.5)$ & $5(12.5)$ \\
Mixed DIC-LIC & $3(7.5)$ & $2(5.0)$ & $3(7.5)$ \\
Other & $5(12.5)$ & $1(2.5)$ & $3(7.5)$ \\
\hline
\end{tabular}

\begin{tabular}{|c|c|c|c|}
\hline \multicolumn{4}{|c|}{ Clinical stage } \\
\hline T2 & 35 (87.5) & $30(75.0)$ & $28(70.0)$ \\
\hline T3 & 0 & $4(10.0)$ & $3(7.5)$ \\
\hline T4 & $4(10.0)$ & $6(15.0)$ & $8(20.0)$ \\
\hline NA & $1(2.5)$ & 0 & $1(2.5)$ \\
\hline NO & $31(77.5)$ & $32(80.0)$ & 33 (82.5) \\
\hline N1 & 5 (15.0) & $8(20.0)$ & $4(10.0)$ \\
\hline NA & $3(7.5)$ & 0 & $3(7.5)$ \\
\hline
\end{tabular}

Abbreviations: $\mathrm{DIC}=$ ductal infiltrating carcinoma; $L I C=$ lobular infiltrating carcinoma; $\mathrm{NA}=$ not available; $\mathrm{PgR}=$ progesterone receptor. The three cohorts of patients were comparable in terms of age at the start of neoadjuvant treatment, basal clinical dimensions, tumoral grade, histotype, PgR and HER2 status, and Ki-67 value.

Table 2. Distribution of clinical disease response (absolute and percentage value) at individual end according to single cohort

\begin{tabular}{|l|c|c|c|}
\hline & Cohort A & Cohort B & Cohort C \\
\hline No. of patients & 40 & 40 & 40 \\
\hline NA & 0 & 2 & 0 \\
\hline Progressive disease & $4(10.0)$ & $1(2.6)$ & 0 \\
\hline Stable disease & $18(45.0)$ & $4(10.5)$ & $2(5.0 \%)$ \\
\hline Partial response & $13(32.5)$ & $17(44.8)$ & $15(37.5 \%)$ \\
\hline Complete response & $5(12.5)$ & $16(42.1)$ & $23(57.5)$ \\
\hline Overall response rate & $45.0 \%$ & $86.8 \%$ & $95.0 \%$ \\
\hline $95 \% \mathrm{Cl}$ & $29.3-61.5$ & $71.9-95.6$ & $83.1-99.4$ \\
\hline
\end{tabular}

Abbreviations: $\mathrm{Cl}=$ confidence interval; $\mathrm{NA}=$ not available 
Table 3. Distribution of clinical disease response (absolute and percentage value) according to months of treatment

\begin{tabular}{|l|c|c|c|}
\hline & Month 4 & Month 8 & Month 12 \\
\hline No. of patients & 117 & 75 & 40 \\
\hline NA & 3 & 5 & 0 \\
\hline Progressive disease & $5(4.3)$ & $1(1.3)$ & 0 \\
\hline Stable disease & $54(46.2)$ & $10(13.4)$ & $2(5.0 \%)$ \\
\hline Partial response & $37(31.6)$ & $33(44.0)$ & $15(37.5 \%)$ \\
\hline Complete response & $21(17.9)$ & $31(41.3)$ & $23(57.5)$ \\
\hline Overall response rate & $49.6 \%$ & $85.3 \%$ & $95.0 \%$ \\
\hline 95\% Cl & $40.2-59.0$ & $75.3-92.4$ & $83.1-99.4$ \\
\hline Abbreviations: Cl= confidence interval; NA=not available. & \\
\hline
\end{tabular}

out of 40, in cohort B, $34(85.0 \%)$ out of 40 and in cohort C, 35 $(87.5 \%)$ out of 40 patients received lumpectomy, respectively. However, no statistical differences were observed between cohorts in relation to the type of surgery performed.

Changes in Ki-67 expression. Baseline and post-treatment Ki-67 expression in 120 cases within each cohort is depicted in Figure 1. At baseline, no difference in Ki-67 index between treatment arms was observed. Letrozole-based treatment resulted in an overall significant reduction in Ki-67 index after treatment $(P<0.000001)$. At post-letrozole treatment, residual histology Ki-67 index was significantly lower compared with baseline in all cohorts $(P<0.00001, P<0.00001$ and $P<0.0001$, respectively), but no significant differences were detected between cohorts (Table 4).

\section{DISCUSSION}

Historically, neoadjuvant endocrine therapy has been limited to patients who were unsuitable for chemotherapy and surgery. Earlier phase II studies with tamoxifen that focused primarily on elderly and/or frail patients often unselected for hormone receptor status of the tumour showed a response rate ranging from $49 \%$ to $68 \%$ (Abrial et al, 2006). Indeed, the third-generation AIs are now acknowledged as the gold standard in the endocrine treatment of oestrogen-responsive postmenopausal breast cancer, in both the neoadjuvant and adjuvant settings (Smith and Dowsett, 2003). However, the superiority in efficacy of AIs over tamoxifen as neoadjuvant treatment for postmenopausal patients with $\mathrm{ER}+1$ $\mathrm{PgR}+$ breast cancer is well known (Eiermann et al, 2001; Smith et al, 2005); among the aromatase inhibitors, the three commercially available agents are clinically and biologically equivalent and therefore likely to have similar neoadjuvant and adjuvant activities (Ellis et al, 2011). Our group has previously shown a very high response rate associated with a significant reduction of Ki-67 index after treatment in neoadjuvant setting based on AI treatment in elderly patients with locally advanced breast cancer (Bottini et al, 2006).

However, the question regarding the optimal duration of neoadjuvant treatment that is able to modulate significantly the biology of the tumour beyond tumour shrinkage and conservative surgery based on AIs is still unknown. Recently, Krainick-Strobel et al (2008) published the prolonged treatment for up to 8 months can result in further tumour volume reduction in some patients with a favourable overall safety and tolerability profile; however, a clear information about the optimum duration of the treatment along with its biological effect is still to be determined. On the basis

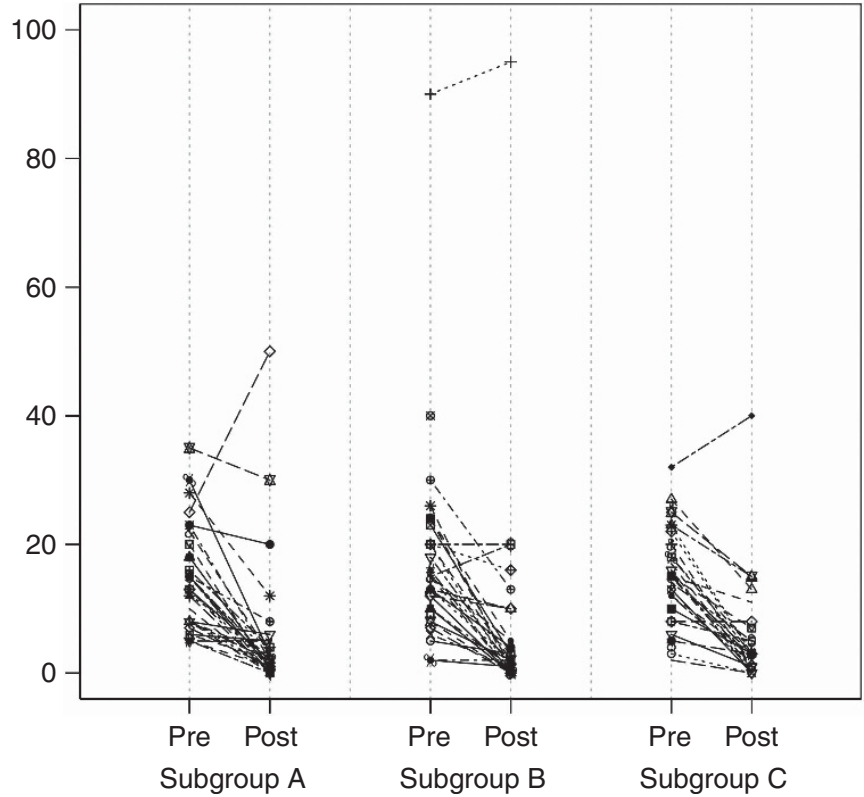

Figure 1. Changes in Ki-67 expression for individual patients at baseline and post-treatment histology according to cohort. The large majority of patients receiving letrozole, independently of the cohort they belong, showed a suppression of Ki-67 expression after treatment.

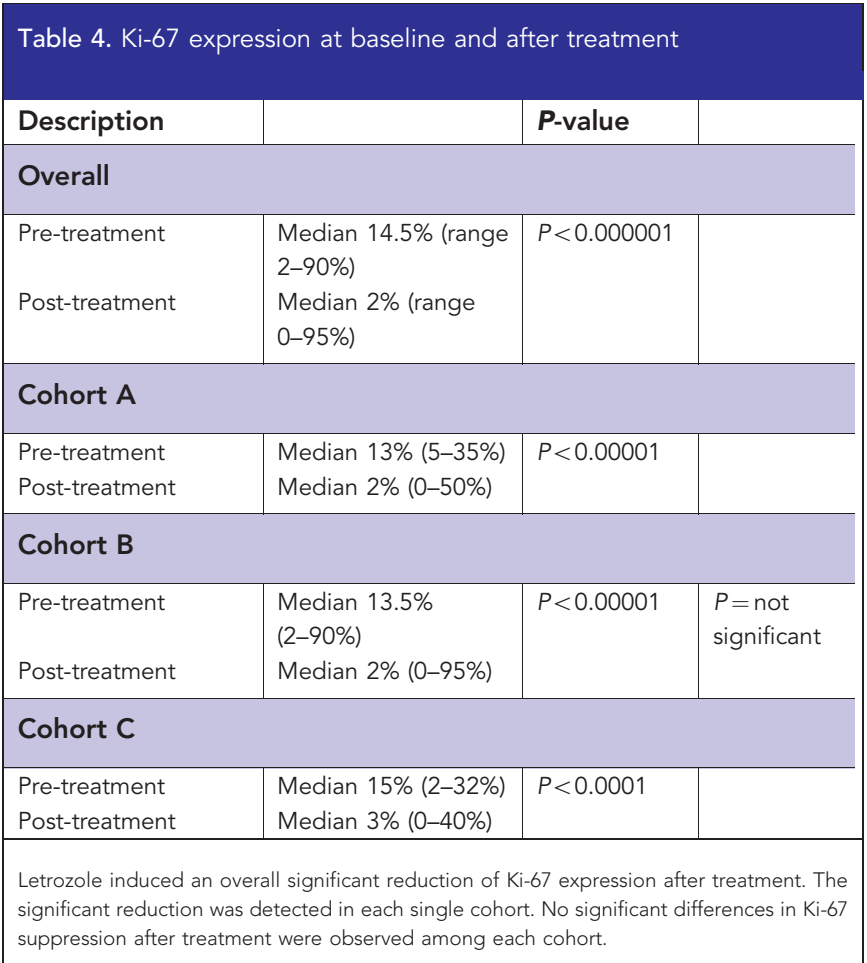

of the clinical data, it was recently agreed by an International Consensus Panel that neoadjuvant hormonal therapy should be continued for not $<4$ months (Berruti et al, 2011b; Kaufmann et al, 2012; Zambetti et al, 2012). However, to provide hard data for enabling evidence-based best practice our group have addressed this issue, from both a clinical and biological point of view, collecting data from patients who have received letrozole 
$2.5 \mathrm{mg} \mathrm{day}^{-1}$ of different duration in the neoadjuvant setting for hormone-responsive locally advanced breast cancer.

Under the conditions of our study, the majority of patients responded to letrozole treatment by 12 months. Also, the ORR was significantly higher with this prolonged duration of administration compared with 4 months, indicating additional benefit from prolonged letrozole treatment. These data are validated by Krainick-Strobel et al (2008), who observed increased overall clinical palpation response rates in intention-to-treat analysis of $72.4 \%$ (CR, 6.9\%; PR, 65.5\%), suggesting incremental benefit from letrozole treatment beyond 4 months' duration (Krainick-Strobel et al, 2008). As far as a comparison is possible, our data also agree with the findings obtained by Renshaw et al (2004), who reported clinical responses from 3 to 12 months neoadjuvant treatment with letrozole $2.5 \mathrm{mg} \mathrm{day}^{-1}$ in 142 postmenopausal women with large operable or locally advanced ER-rich breast cancer (Renshaw et al, 2004).

This tendency of an increased ORR with the increased duration of the treatment administration was also reflected in the BCS rate from $80.0 \%$ in cohort A to $87.5 \%$ in cohort C, respectively. This underlines the beneficial effect of neoadjuvant letrozole treatment for longer than 4 months; considering also that the observed adverse events related to letrozole were not unexpected and mostly mild-to-moderate in severity, even the treatment was longer.

The response to neoadjuvant treatment is frequently utilised as a surrogate of outcome with chemotherapy, as it has been shown to be associated with a longer disease-free survival and overall survival compared with no response (US Department of Health and Human Services, 2012). In particular, it has been assumed that pathological complete remission is a valid surrogate of long-term survival and cure from breast cancer (Fisher et al, 1998; Guarneri et al, 2006; Akashi-Tanaka et al, 2007; Berruti et al, 2011a). However, pathCR can be achieved only in a minority of patients with ER-positive disease irrespective of the treatment adopted (chemotherapy or hormone therapy). Recent consensus papers on neoadjuvant therapy in breast cancer indicate that pathCR rates ranges from $2 \%$ to $10 \%$ in those patients whose tumours that express ER (Berruti et al, 2011b; Kaufmann et al, 2012; Zambetti et al, 2012). However, our study showed for the first time that to achieve an optimal pathCR rate in ER-positive disease, the duration of the endocrine treatment administration is critical, increasing up to $17.5 \%$ with 12 months treatment.

In this study, we have treated elderly patients with high level of tumour ER expression and it is possible that higher tumour ER levels correlate with a higher probability of response, as reported in two randomised neoadjuvant trials in postmenopausal patients with ER-positive disease (Ellis et al, 2001; Smith et al, 2005). It is also recognised in advanced disease that it may take many months to obtain the maximum response, but that has not as yet translated into practice for primary cancers. The pathCR obtained with 12 months letrozole therapy in our study is indeed superior than that expected with chemotherapy and is preferable in this setting. All these data suggest the oncologists should administer hormone therapy of longer duration to obtain not only the best tumour response for breast-conserving surgery but also to achieve a pathCR to offer the best outcome as possible to their breast cancer patients.

From the biological point of view, as expected, letrozole reduced significantly Ki-67 expression after treatment in all arms. A positive significant correlation between the ER level and the degree of Ki-67 suppression after 2 and 12 weeks of endocrine treatment has been reported (Dowsett et al, 2005). We hypothesise that the level of expression of ER, and maybe also PgR (only few patients were negative), might also be correlated with the probability of response to neoadjuvant hormone therapy with prolonged therapy. In retrospective studies, high baseline $\mathrm{Ki}-67$ was found to be an independent factor predictive for pathCR at multivariate analyses
(Petit et al, 2004; Colleoni et al, 2010). Even though we did not find any correlations with basal expression of Ki-67 (cutoff used $>14 \%$ ) and pathCR in any arm, it might be possible to consider that the high baseline expression of Ki-67 combined with higher ER expression could be helpful for oncologists in selecting patients who would benefit from longer administration of letrozole in neoadjuvant setting. It is worth noting that changes in Ki-67 in our series did not differ comparing patients who received 12-month letrozole therapy with those with shorter drug exposure. This observation suggests that reduction in $\mathrm{Ki}-67$ is not predictive of pathCR and underlines that treatment-induced changes in proliferative activity and apoptosis follow independent mechanisms.

In conclusion, prolonged neoadjuvant letrozole treatment is well tolerated with a favourable toxicity profile and results in further tumour volume reduction, and thus may provide incremental benefit to patients for conservative surgery and the induction of a high rate of pathCR.

\section{REFERENCES}

Abrial C, Mouret-Reynier MA, Cure H, Feillel V, Leheurteur M, Lemery S, Le Bouedec G, Durando X, Dauplat J, Chollet P (2006) Neoadjuvant endocrine therapy in breast cancer. Breast 15(1): 9-19.

Akashi-Tanaka S, Omatsu M, Shimizu C, Ando M, Terada K, Shien T, Kinoshita T, Fujiwara Y, Seki K, Hasegawa T, Fukutomi T (2007) Favorable outcome in patients with breast cancer in the presence of pathological response after neoadjuvant endocrine therapy. Breast 16(5): $482-488$.

Berruti A, Brizzi MP, Generali D, Ardine M, Dogliotti L, Bruzzi P, Bottini A (2008) Presurgical systemic treatment of nonmetastatic breast cancer: facts and open questions. Oncologist 13(11): 1137-1148.

Berruti A, Generali D, Bertaglia V, Brizzi MP, Mele T, Dogliotti L, Bruzzi P, Bottini A (2011a) Intermediate endpoints of primary systemic therapy in breast cancer patients. J Natl Cancer Inst Monogr 2011(43): 142-146.

Berruti A, Generali D, Kaufmann M, Puztai L, Curigliano G, Aglietta M, Gianni L, Miller WR, Untch M, Sotiriou C, Daidone M, Conte P, Kennedy D, Damia G, Petronini P, Di Cosimo S, Bruzzi P, Dowsett M, Desmedt C, Mansel RE, Olivetti L, Tondini C, Sapino A, Fenaroli P, Tortora G, Thorne H, Bertolini F, Ferrozzi F, Danova M, Tagliabue E, de Azambuja E, Makris A, Tampellini M, Dontu G, Van't Veer L, Harris AL, Fox SB, Dogliotti L, Bottini A (2011b) International expert consensus on primary systemic therapy in the management of early breast cancer: highlights of the Fourth Symposium on Primary Systemic Therapy in the Management of Operable Breast Cancer, Cremona, Italy (2010). J Natl Cancer Inst Monogr 2011(43): 147-151.

Bottini A, Generali D, Brizzi MP, Fox SB, Bersiga A, Bonardi S, Allevi G, Aguggini S, Bodini G, Milani M, Dionisio R, Bernardi C, Montruccoli A, Bruzzi P, Harris AL, Dogliotti L, Berruti A (2006) Randomized phase II trial of letrozole and letrozole plus low-dose metronomic oral

cyclophosphamide as primary systemic treatment in elderly breast cancer patients. J Clin Oncol 24(22): 3623-3628.

Carpenter R, Doughty JC, Cordiner C, Moss N, Gandhi A, Wilson C, Andrews C, Gui G, Skene A (2010) A multicenter study to determine the optimum duration of neoadjuvant letrozole on tumor regression to permit breast-conserving surgery: final analyses. J Clin Oncol 28(15, Suppl): 670.

Cavazzoni A, Bonelli MA, Fumarola C, La Monica S, Airoud K, Bertoni R, Alfieri RR, Galetti M, Tramonti S, Galvani E, Harris AL, Martin LA, Andreis D, Bottini A, Generali D, Petronini PG (2012) Overcoming acquired resistance to letrozole by targeting the PI3K/AKT/mTOR pathway in breast cancer cell clones. Cancer Lett 323(1): 77-87.

Colleoni M, Bagnardi V, Rotmensz N, Viale G, Mastropasqua M, Veronesi P, Cardillo A, Torrisi R, Luini A, Goldhirsch A (2010) A nomogram based on the expression of $\mathrm{Ki}-67$, steroid hormone receptors status and number of chemotherapy courses to predict pathological complete remission after preoperative chemotherapy for breast cancer. Eur J Cancer 46(12): 2216-2224.

CTCAE, Common Terminology Criteria for Adverse Events v. 4.03.. MNCI, National Institute of Health, Rockville, MD, USA (2009) available at 
http://evs.nci.nih.gov/ftp1/CTCAE/CTCAE_4.03_2010-0614_QuickReference_8.5 × 11.pdf (accessed August 2011).

Dixon JM, Renshaw L, Macaskill EJ, Young O, Murray J, Cameron D, Kerr GR, Evans DB, Miller WR (2009) Increase in response rate by prolonged treatment with neoadjuvant letrozole. Breast Cancer Res Treat 113(1): $145-151$.

Dowsett M, Smith IE, Ebbs SR, Dixon JM, Skene A, Griffith C, Boeddinghaus I, Salter J, Detre S, Hills M, Ashley S, Francis S, Walsh G, Trialists I (2005) Short-term changes in Ki-67 during neoadjuvant treatment of primary breast cancer with anastrozole or tamoxifen alone or combined correlate with recurrence-free survival. Clin Cancer Res 11(2, Part 2): 951s-958ss.

Eiermann W, Paepke S, Appfelstaedt J, Llombart-Cussac A, Eremin J, Vinholes J, Mauriac L, Ellis M, Lassus M, Chaudri-Ross HA, Dugan M, Borgs M. Letrozole Neo-Adjuvant Breast Cancer Study G (2001) Preoperative treatment of postmenopausal breast cancer patients with letrozole: a randomized double-blind multicenter study. Ann Oncol 12(11): 1527-1532.

Eisenhauer EA, Therasse P, Bogaerts J, Schwartz LH, Sargent D, Ford R, Dancey J, Arbuck S, Gwyther S, Mooney M, Rubinstein L, Shankar L, Dodd L, Kaplan R, Lacombe D, Verweij J (2009) New response evaluation criteria in solid tumours: revised RECIST guideline (version 1.1). Eur J Cancer 45(2): 228-247.

Ellis MJ, Coop A, Singh B, Mauriac L, Llombert-Cussac A, Janicke F, Miller WR, Evans DB, Dugan M, Brady C, Quebe-Fehling E, Borgs M (2001) Letrozole is more effective neoadjuvant endocrine therapy than tamoxifen for ErbB-1- and/or ErbB-2-positive, estrogen receptor-positive primary breast cancer: evidence from a phase III randomized trial. J Clin Oncol 19(18): 3808-3816.

Ellis MJ, Suman VJ, Hoog J, Lin L, Snider J, Prat A, Parker JS, Luo J, DeSchryver K, Allred DC, Esserman LJ, Unzeitig GW, Margenthaler J, Babiera GV, Marcom PK, Guenther JM, Watson MA, Leitch M, Hunt K, Olson JA (2011) Randomized phase II neoadjuvant comparison between letrozole, anastrozole, and exemestane for postmenopausal women with estrogen receptor-rich stage 2 to 3 breast cancer: clinical and biomarker outcomes and predictive value of the baseline PAM50-based intrinsic subtype - ACOSOG Z1031. J Clin Oncol 29(17): 2342-2349.

Fasching PA, Heusinger K, Haeberle L, Niklos M, Hein A, Bayer CM, Rauh C, Schulz-Wendtland R, Bani MR, Schrauder M, Kahmann L, Lux MP, Strehl JD, Hartmann A, Dimmler A, Beckmann MW, Wachter DL (2011) Ki67, chemotherapy response, and prognosis in breast cancer patients receiving neoadjuvant treatment. BMC Cancer 11: 486.

Fiorentino C, Berruti A, Bottini A, Bodini M, Brizzi MP, Brunelli A, Marini U, Allevi G, Aguggini S, Tira A, Alquati P, Olivetti L, Dogliotti L (2001) Accuracy of mammography and echography versus clinical palpation in the assessment of response to primary chemotherapy in breast cancer patients with operable disease. Breast Cancer Res Treat 69(2): 143-151.

Fisher B, Bryant J, Wolmark N, Mamounas E, Brown A, Fisher ER, Wickerham DL, Begovic M, DeCillis A, Robidoux A, Margolese RG, Cruz Jr AB, Hoehn JL, Lees AW, Dimitrov NV, Bear HD (1998) Effect of preoperative chemotherapy on the outcome of women with operable breast cancer. J Clin Oncol 16(8): 2672-2685.

Generali D, Buffa FM, Berruti A, Brizzi MP, Campo L, Bonardi S, Bersiga A, Allevi G, Milani M, Aguggini S, Papotti M, Dogliotti L, Bottini A, Harris AL, Fox SB (2009) Phosphorylated ERalpha, HIF-1alpha, and MAPK signaling as predictors of primary endocrine treatment response and resistance in patients with breast cancer. J Clin Oncol 27(2): 227-234.

Guarneri V, Broglio K, Kau SW, Cristofanilli M, Buzdar AU, Valero V, Buchholz T, Meric F, Middleton L, Hortobagyi GN, Gonzalez-Angulo AM (2006) Prognostic value of pathologic complete response after primary chemotherapy in relation to hormone receptor status and other factors. J Clin Oncol 24(7): 1037-1044.

Kaufmann M, Hortobagyi GN, Goldhirsch A, Scholl S, Makris A, Valagussa P, Blohmer JU, Eiermann W, Jackesz R, Jonat W, Lebeau A, Loibl S, Miller W, Seeber S, Semiglazov V, Smith R, Souchon R, Stearns V, Untch M, von Minckwitz G (2006) Recommendations from an international expert panel on the use of neoadjuvant (primary) systemic treatment of operable breast cancer: an update. J Clin Oncol 24(12): 1940-1949.

Kaufmann M, von Minckwitz G, Mamounas EP, Cameron D, Carey LA, Cristofanilli M, Denkert C, Eiermann W, Gnant M, Harris JR, Karn T, Liedtke C, Mauri D, Rouzier R, Ruckhaeberle E, Semiglazov V, Symmans WF, Tutt A, Pusztai L (2012) Recommendations from an international consensus conference on the current status and future of neoadjuvant systemic therapy in primary breast cancer. Ann Surg Oncol 19(5): 1508-1516.

Krainick-Strobel UE, Lichtenegger W, Wallwiener D, Tulusan AH, Janicke F, Bastert G, Kiesel L, Wackwitz B, Paepke S (2008) Neoadjuvant letrozole in postmenopausal estrogen and/or progesterone receptor positive breast cancer: a phase IIb/III trial to investigate optimal duration of preoperative endocrine therapy. BMC Cancer 8: 62.

Margariti N, Fox SB, Bottini A, Generali D (2011) 'Overcoming breast cancer drug resistance with mTOR inhibitors'. Could it be a myth or a real possibility in the short-term future? Breast Cancer Res Treat 128(3): 599-606.

Mlineritsch B, Tausch C, Singer C, Luschin-Ebengreuth G, Jakesz R, Ploner F, Stierer M, Melbinger E, Menzel C, Urbania A, Fridrik M, Steger G, Wohlmuth P, Gnant M, Greil R. Austrian Breast CCSG (2008) Exemestane as primary systemic treatment for hormone receptor positive post-menopausal breast cancer patients: a phase II trial of the Austrian Breast and Colorectal Cancer Study Group (ABCSG-17). Breast Cancer Res Treat 112(1): 203-213.

Petit T, Wilt M, Velten M, Millon R, Rodier JF, Borel C, Mors R, Haegele P, Eber M, Ghnassia JP (2004) Comparative value of tumour grade, hormonal receptors, Ki-67, HER-2 and topoisomerase II alpha status as predictive markers in breast cancer patients treated with neoadjuvant anthracycline-based chemotherapy. Eur J Cancer 40(2): 205-211.

Renshaw LMJ, Young O, Cameron D, Miller WR, Dixon JM (2004) Is there an optimal duration of neoadjuvant letrozole therapy? Breast Cancer Res Treat 88: S36-S37.

Sheri A, Dowsett M (2012) Developments in Ki67 and other biomarkers for treatment decision making in breast cancer. Ann Oncol 23(Suppl 10): $\mathrm{x} 219-\mathrm{x} 227$.

Smith IE, Dowsett M (2003) Aromatase inhibitors in breast cancer. N Engl J Med 348(24): 2431-2442.

Smith IE, Dowsett M, Ebbs SR, Dixon JM, Skene A, Blohmer JU, Ashley SE, Francis S, Boeddinghaus I, Walsh G, Group IT (2005) Neoadjuvant treatment of postmenopausal breast cancer with anastrozole, tamoxifen, or both in combination: the Immediate Preoperative Anastrozole, Tamoxifen, or Combined with Tamoxifen (IMPACT) multicenter doubleblind randomized trial. J Clin Oncol 23(22): 5108-5116.

US Department of Health and Human Services (2012) Pathologic Complete Response in Neoadjuvant Treatment of High-Risk Early-Stage Breast Cancer: Use as an Endpoint to Support Accelerated Approval. FaDA, Center for Drug Evaluation and Research (CDER): Silver Spring, MD.

Yancik R, Wesley MN, Ries LA, Havlik RJ, Edwards BK, Yates JW (2001) Effect of age and comorbidity in postmenopausal breast cancer patients aged 55 years and older. JAMA 285(7): 885-892.

Zambetti M, Mansutti M, Gomez P, Lluch A, Dittrich C, Zamagni C, Ciruelos E, Pavesi L, Semiglazov V, De Benedictis E, Gaion F, Bari M, Morandi P, Valagussa P, Luca G (2012) Pathological complete response rates following different neoadjuvant chemotherapy regimens for operable breast cancer according to ER status, in two parallel, randomized phase II trials with an adaptive study design (ECTO II). Breast Cancer Res Treat 132(3): 843-851.

This work is published under the standard license to publish agreement. After 12 months the work will become freely available and the license terms will switch to a Creative Commons AttributionNonCommercial-Share Alike 3.0 Unported License. 